\title{
A simple method of weighing the heart
}

\author{
A. G. MARSHALL \\ From The Royal Hospital, Wolverhampton
}

SYNOPSIS A simple method of dividing and weighing the heart is described. It is quick to perform and ratios between the left and right ventricles and the total weight of the heart are remarkably constant.

Analysis of 788 cases shows that these ratios are of value in the diagnosis after death of systemic and pulmonary hypertension. This is applicable to both sexes at all ages.

An unexpected finding was a significant correlation between pulmonary hypertension and acute massive pulmonary embolism, of which the prophylactic and therapeutic implications are mentioned.

The value of the method in childhood and infancy is indicated.

Weighing the heart is a usual procedure in routine necropsies but its value is restricted in any particular case by ignorance of the normal weight and by the difficulty of determining the contribution of each part of the heart to a variation from the supposed normal. A method of dividing the organ in order to weigh its various parts was described by Lewis (1914) but the procedure takes some weeks to complete and this limits its value in routine work. Some pathologists estimate hypertrophy of the ventricles by measuring the thickness of their walls but in our hands this has not been successful owing to the irregularity of the endocardial surfaces. Others assess the presence of pulmonary hypertension by measurements of the pulmonary vessels in histological sections (Heath and Whitaker, 1955) but we have found this unsatisfactory for routine work.

Some years ago a standard technique for dividing and weighing the heart was adopted, and having collected data from 788 cases the findings are presented here in the hope that the method will be useful to others. The technique was purposely made as simple as possible as time is often limited in routine work and great accuracy was deliberately sacrificed for the same reason. The whole procedure takes only a few minutes and results in fairly comparable figures. The whole of the interventricular septum is weighed with the left ventricle and no attempt is made to separate the two auricles; the pericardial fat and coronary vessels are not removed from the surface of the heart. It was intended to avoid defining the weight of the normal heart by

Received for publication 13 July 1960. calculating the ratios of the weights of its various parts.

\section{METHOD}

Although Lewis (1914) explains his method at length, Herrmann and Wilson (1922) found that his directions were not explicit enough to prevent misunderstanding. Our technique is therefore set out below in full detail of each step we actually take and illustrated in Figs. 1 to 3.

1 The thoracic contents are removed in toto and the heart is not removed from them until step 7 below. Running water is used when required throughout the examination.

2 After examining the remainder of these organs and opening the pericardium to its apex, the right auricle is opened with scissors and examined with the tricuspid valve.

3 A long knife is then passed through the tricuspid orifice to the apex of the right ventricle and this is opened by an incision along the length of its extreme outer border.

4 With scissors laid flat against the right ventricular surface of the interventricular septum, the right ventricle is cut off it from apex to base along its anterior junction with it. None of the right ventricle now remains attached anteriorly to the septum, and the incision is continued through the pulmonary valve and into the pulmonary artery and its branches (Fig. 1).

5 Having examined the right chambers, steps 2 and 3 are now copied exactly on the left side thus exposing the left auricle, mitral valve, and most of the left ventricle.

6 The aortic valve and thoracic aorta are now opened by cutting upwards through the mitral valve and the aortic valve with scissors.

7 The heart is now removed from the other viscera by lifting it vertically, apex upwards, with the remainder 


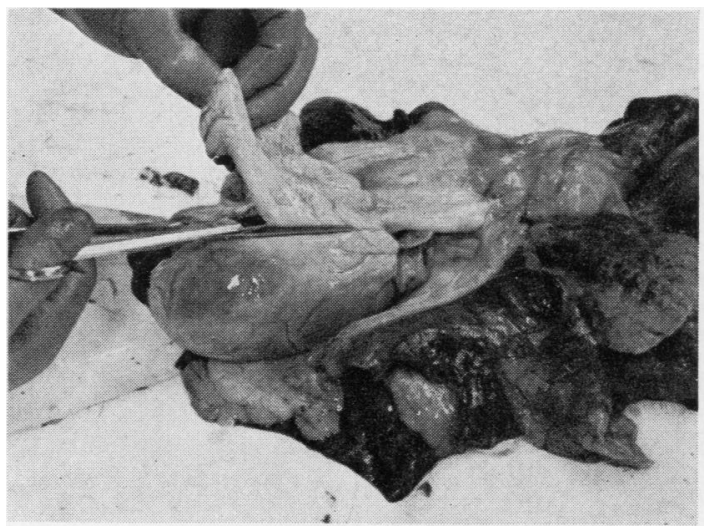

FIG. 1. Cutting the right ventricle from the right side of the septum anteriorly.

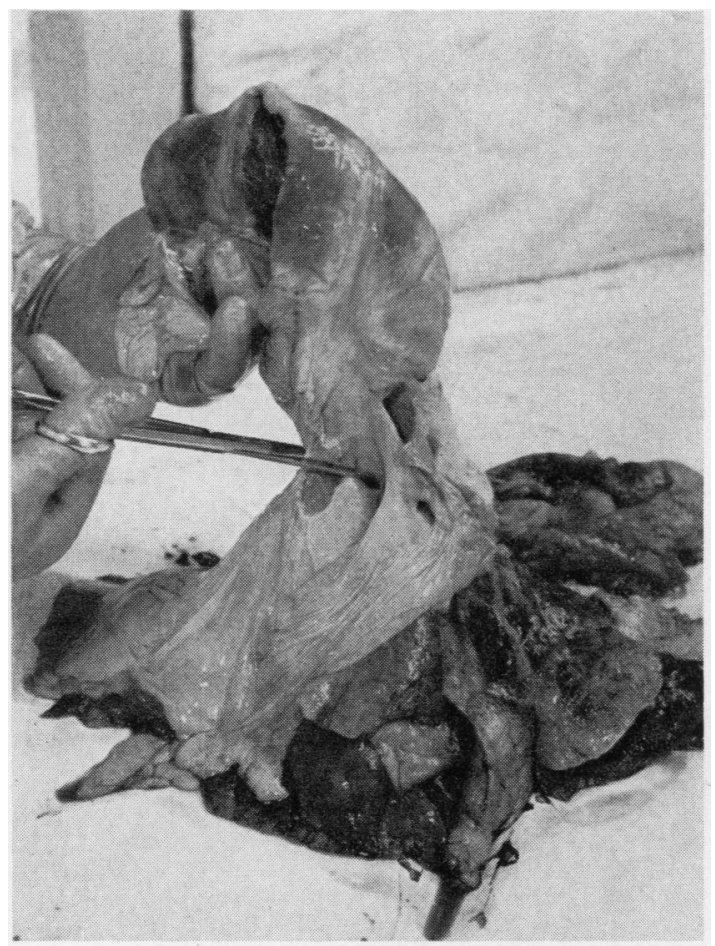

FIG. 2. Removing the heart from the other thoracic viscera. Note the manner in which the anterior edge of the right ventricle has been cut from its junction with the septum. of the thoracic viscera hanging from it. The pulmonary veins and venae cavae are now divided at their junctions with the auricles, and the aorta and pulmonary arteries are divided at the level of the upper edges of their valve cusps. It is most important that these vessels be divided at these respective levels and we draw attention to the possibility of error at this stage (Fig. 2).

8 All the remaining blood clot is washed away and lightly adherent thrombus removed with forceps. The heart is now weighed.

9 The coronary arteries are now opened and examined as may be desired.

10 The posterior attachment of the right ventricle to the septum is now divided, again with scissors laid flat against the right ventricular surface of the septum.

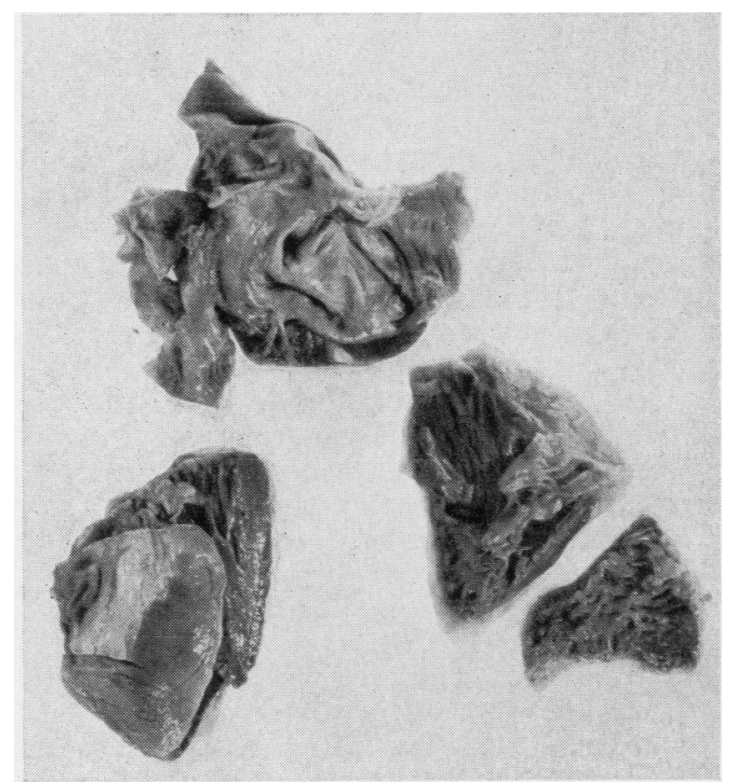

FIG. 3. The heart as finally divided. Above, the auricles; below on the left, the left ventricle; below on the right, the right ventricle in its two parts.

11 The auricles are now removed by cutting them off the ventricles or pieces of ventricle along the coronary sulcus, and joining these incisions across the top of the septum. The heart is thus divided into four pieces $(a)$ the auricles, $(b)$ the left ventricle attached to the septum, and (c) the right ventricle in two pieces. The two ventricles are weighed, recording $(b)$ as the left ventricle and $(c)$ as the right (Fig. 3). Simple ratios are calculated as follows to one place of decimals.

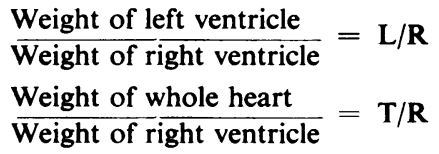




$$
\frac{\text { Weight of whole heart }}{\text { Weight of left ventricle }}=\mathrm{T} / \mathrm{L}
$$

The weight of the auricles can be determined by subtraction.

\section{RESULTS}

The material available consists of the data from 788 post-mortem examinations, being all the routine necropsies performed at one hospital in the years 1954-57, except for a small number which had to be discarded on the grounds of insufficient information. There are 650 adults ( 429 of them males), 20 adolescents aged 10 to 20 years, 23 children aged 1 to 10 years, and 95 infants under 1 year of age. Most of the discards were infants whose hearts had not been divided.

Our attention was first directed to adults and the findings were considered for each sex in age groups. As usual in routine hospital work there is a preponderance of cases in the sixth and seventh decades. The numbers in the younger age groups from which it might be expected to discover the normal values are small but from them and from accident cases ideas were formed as to the probable directions in which deviations might be expected to occur. It became necessary to place an arbitrary maximum for the weight of the normal heart in each sex in order to determine the approximate normal values for the new measurements. There is no real agreement on the maximum weight of the human heart (Zeek, 1942) and it has been the custom for many years in our department to regard it as $350 \mathrm{~g}$. for males and $300 \mathrm{~g}$. for females. As we have no facilities for weighing the bodies (Bartels and Smith, 1932), these figures were taken as normal and have proved satisfactory. Indeed, raising the values to $400 \mathrm{~g}$. and 350 g. respectively did not greatly affect the overall results but did include a number of clinically abnormal hearts in the normal groups.

DISTRIBUTION OF HEART WEIGHTS At this point it seems worth while to examine the distribution of heart weights in this material. Largely on the basis of the clinical history in each case and with due regard to the general post-mortem findings, all the adult hearts (20 years and above) were divided into three populations.

1 No vascular disease or normal This refers in fact to the absence of systemic hypertension or chronic pulmonary disease (see 3 below), and includes conditions other than hypertension which might give rise to cardiac hypertrophy, e.g., aortic valvular stenosis, pericarditis, etc.

2 Systemic hypertension A clinical history consistent with it and blood pressure above $140 / 90 \mathrm{~mm}$. Hg.
3 Pulmonary disease excluding hypostatic pneumonia or single attack of lobar pneumonia Conditions which might reasonably be expected to give rise to pulmonary hypertension such as mitral stenosis were included. When systemic hypertension was also present, the case was placed in group 2.

Figure 4 shows the distribution of total heart weights in these three classes. There is some tendency to support our arbitrary estimate of normal heart weight, since in males the hearts of only eight $(3.5 \%)$ of cases of systemic hypertension fall below $350 \mathrm{~g}$. and in females only five $(5.5 \%)$ fall below $300 \mathrm{~g}$. It is possible that in some of these patients a sufficient degree of cardiac hypertrophy had not been achieved to bring the heart weight above these values. It is admitted that in each sex roughly one third of the 'normals' is found above these weights but these, of course, include hearts enlarged for some reason other than hypertension and those where there was insufficient evidence for a firm diagnosis of hypertensive disease. In both sexes the cases of pulmonary disease are fairly evenly distributed throughout the range; total heart weight is little help in the diagnosis of pulmonary hypertension.

In normal hearts the weight of the right ventricle by our method is about 80 to $100 \mathrm{~g}$. and the left ventricle weighs about $100 \mathrm{~g}$. more. In females these figures are smaller by some $20 \mathrm{~g}$. The weight of the auricles was more variable and we have failed to attach any significance to these variations. In normal hearts of whatever weight and in both sexes the ratios were remarkably constant as follows:$\mathrm{L} / \mathrm{R} 2$ to $3, \mathrm{~T} / \mathrm{R} 3$ to 5 , and T/L 1.5 to 2 .

In left ventricular hypertrophy it would be expected that the first two ratios would become larger and the last smaller. In known cases of systemic hypertension or aortic valvular disease $L / R$ and $T / R$ were found to be increased beyond 3 and 5 respectively, though in some cases only one was raised. It seemed therefore that when $L / R$ equals or exceeds 3 and/or $T / R$ equals or exceeds 5 (values 'raised' or 'increased') there is left ventricular hypertrophy associated with systemic hypertension unless some other explanation can be found.

Lewis (1914) remarks that the commonest type of cardiac hypertrophy is a uniform hypertrophy and in this case these ratios could be either normal or increased.

In the conditions which are usually associated with pulmonary hypertension such as mitral stenosis, Fallot's tetralogy, and pulmonary fibrosis the ratio $T / L$ is greater than $\mathbf{L} / \mathbf{R}$ or equal to it ('ratios reversed') and this was the case in $58 \%$ of infants mostly in the first few days of life (Table IV). Such a deviation would be expected in right ventricular 
A simple method of weighing the heart

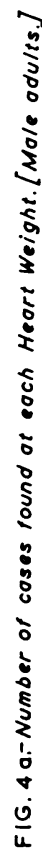
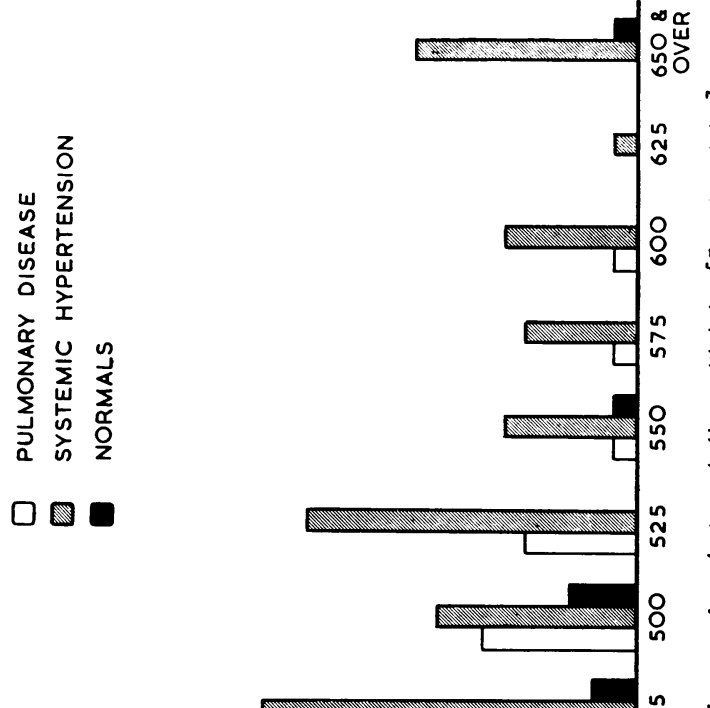

5
$\vdots$
$\vdots$
$\vdots$
5
5
$\vdots$
$\vdots$
$\vdots$
$\vdots$
$\vdots$
$\vdots$
$\vdots$
5
$\vdots$
$\vdots$
0
$\vdots$
$\vdots$
$\vdots$
$\vdots$
$\vdots$

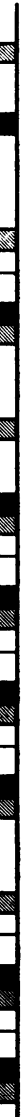

우ํำ

00
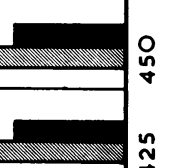

$\stackrel{n}{ษ}$

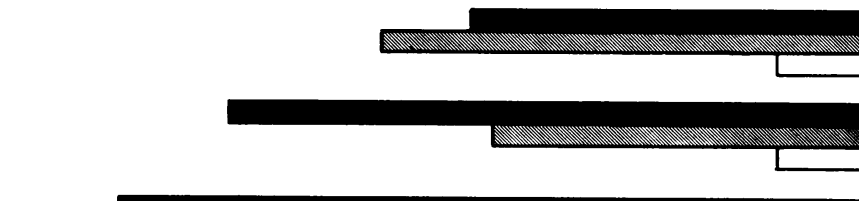

웅
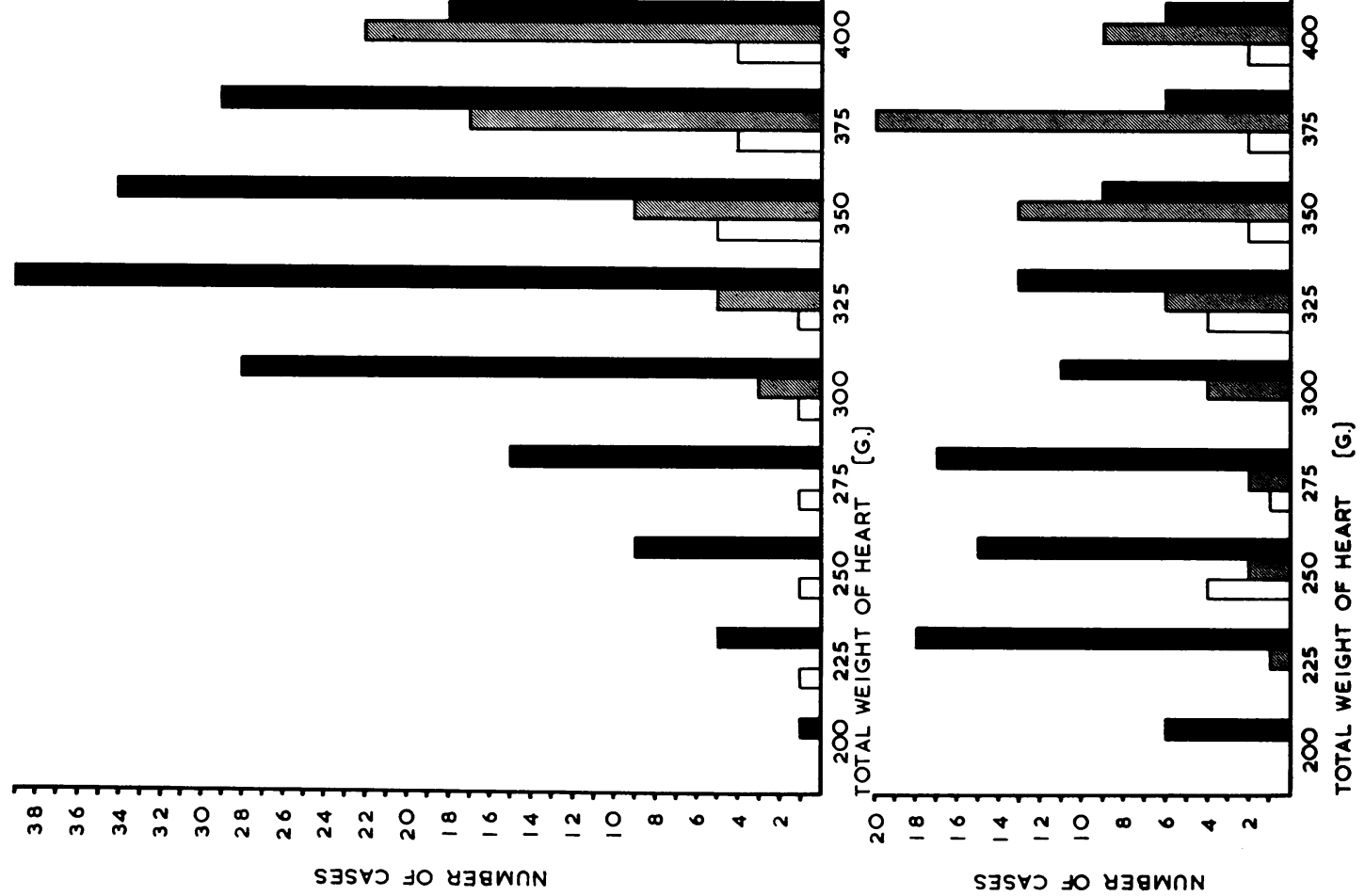
hypertrophy and it was therefore concluded that it indicates pulmonary hypertension if other explanations are lacking.

In order to test the validity of these two conclusions the adult cases were divided first into two main categories, those with normal and those with increased heart weights using the arbitrary standards. Each category was subdivided into three groups, namely, (a) ratios normal $\mathrm{L} / \mathrm{R}<3, \mathrm{~T} / \mathrm{R}<5$, and $T / L<L / R ;(b)$ ratios raised $L / R \geqslant 3$, and/or $T / R \geqslant 5$, $T / L<L / R ;(c)$ ratios reversed $T / L \geqslant L / R(D \leqslant 0)$.

The 788 cases were allocated to these groups in the three categories as defined above, those having no vascular disease, those having clinical systemic hypertension, and those dying of pulmonary disease excluding terminal or hypostatic pneumonia. The few cases of mitral stenosis or Fallot's tetralogy were included as pulmonary disease. Being puzzled as to the place of acute pulmonary embolism, such cases were at first placed in a separate category. The tabulated results for the two sexes in three age groups are shown in Table I. The results of simple significance tests on these figures are also shown and they tend to confirm our conclusions that 'raised' values of $L / R$ and/or $T / R$ are associated with systemic hypertension while 'ratios reversed' in which $D$ $(\mathrm{L} / \mathrm{R}-\mathrm{T} / \mathrm{L})$ is 0 or less than 0 are associated with pulmonary hypertension. The ratios $L / R, T / R$, and for $D(L / R-T / L)$ were therefore analysed further as shown in Figs. 5, 6, and 7. It can be seen that (1) $L / R$ is 3 or more in only $25(15 \%)$ of males and in $15(14 \%)$ of females with no hypertensive

TABLE I

CLASSIFIED RESULTS IN ADULTS AND NUMBER OF CASES IN EACH CATEGORY

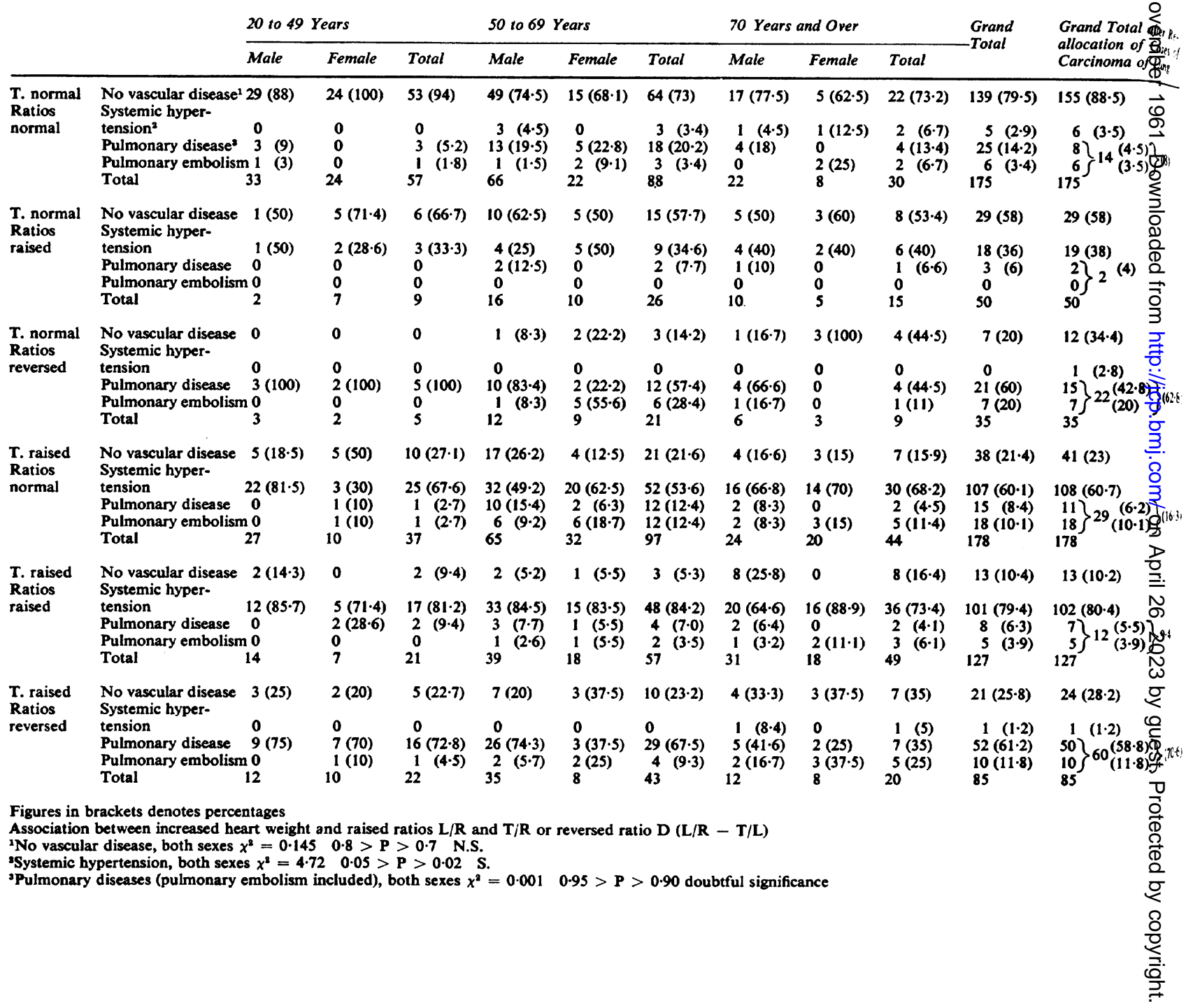


disease (normals) and there are no cases of pulmonary disease in either sex with $L / R \geqslant 3$. The cases of systemic hypertension are, however, rather widely scattered. (2) $T / R$ is 5 or more in $44(22 \%)$ of males and in $24(25 \%)$ of females regarded as 'normal'; there is only one case of pulmonary disease, a female. Again systemic hypertension is quite widely distributed. (3) D (L/R-T/L), in which a value of 0 or less includes $48(87.5 \%)$ cases of pulmonary disease in males and $19(90 \%)$ cases in females. In systemic hypertension (which takes precedence when both conditions are present) $5 \%$ and $2 \%$ respectively fall in this range and in normals the incidence for the two sexes is $1 \%$ and $12 \%$.
In order to examine further the variability of these three series and of the total heart weights probability curves were constructed using a log. normal scale except in the case of $D$ where there are negative values (Figs. 8 to 11 ). In each case the $95 \%$ range $(2.5 \%$ to $97.5 \%)$ is shown and the median can be derived from them for each category. These curves indicate clearly the variability of each series and very approximate significance tests are shown in Table II. The only occasions when there is no apparent significant variation concern the curves for 'all cases' in $T / R$ and $D$. It seems reasonable to suppose therefore that the variations in the heart weights in $L / R$, $T / R$, and $D$ in the various categories are distinct

TABLE II

ANALYSIS OF FIGURES 8 TO 11

\begin{tabular}{|c|c|c|c|c|}
\hline No. of Cases & Median & $95 \%$ Range & $\begin{array}{c}\sigma \text { (Approxi- } \\
\text { mately) }\end{array}$ & $\begin{array}{l}\text { Difference of } \quad \text { S.E. of Difference } \\
\text { Median from } \\
\text { Median of Normal }\end{array}$ \\
\hline
\end{tabular}

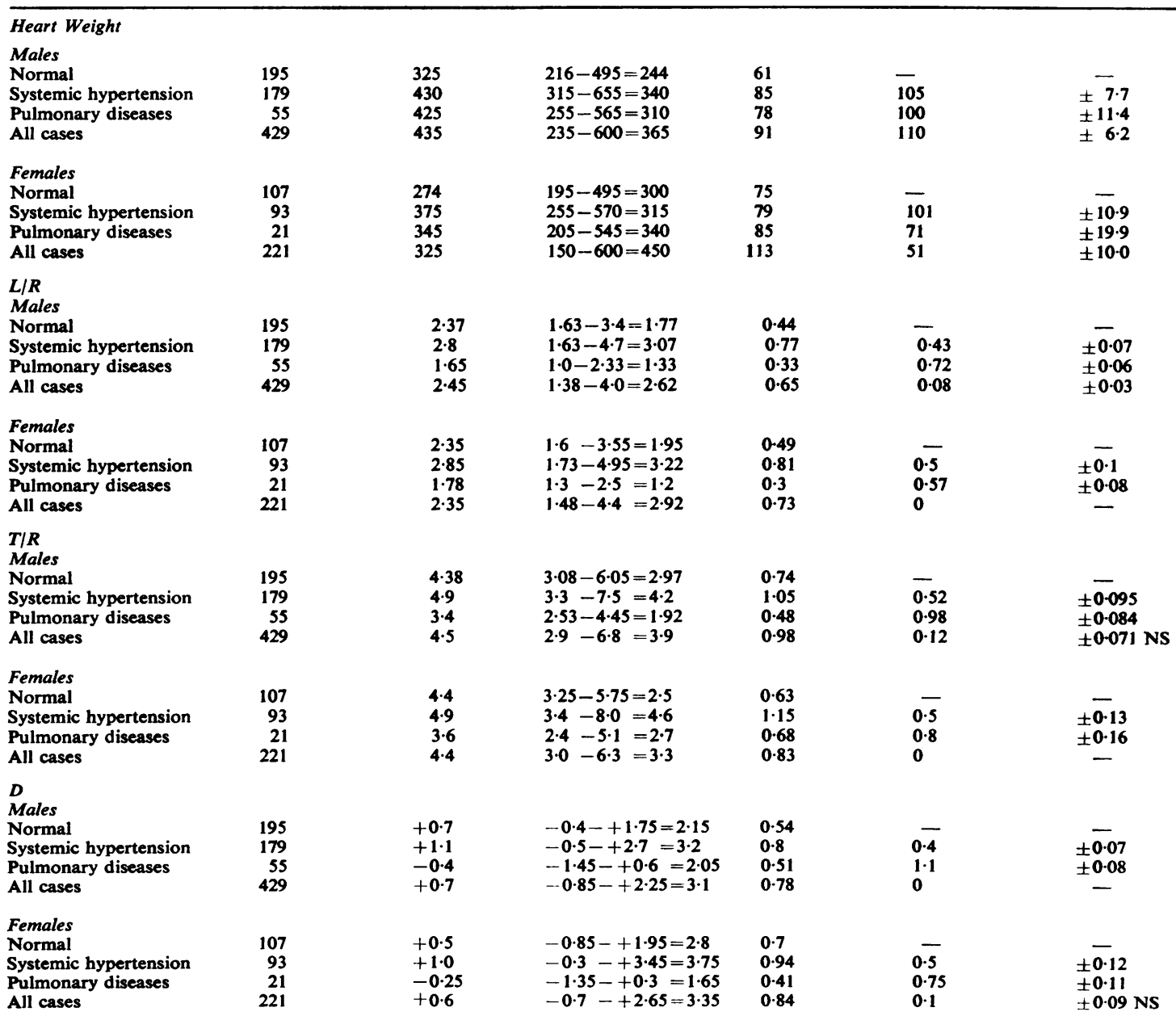




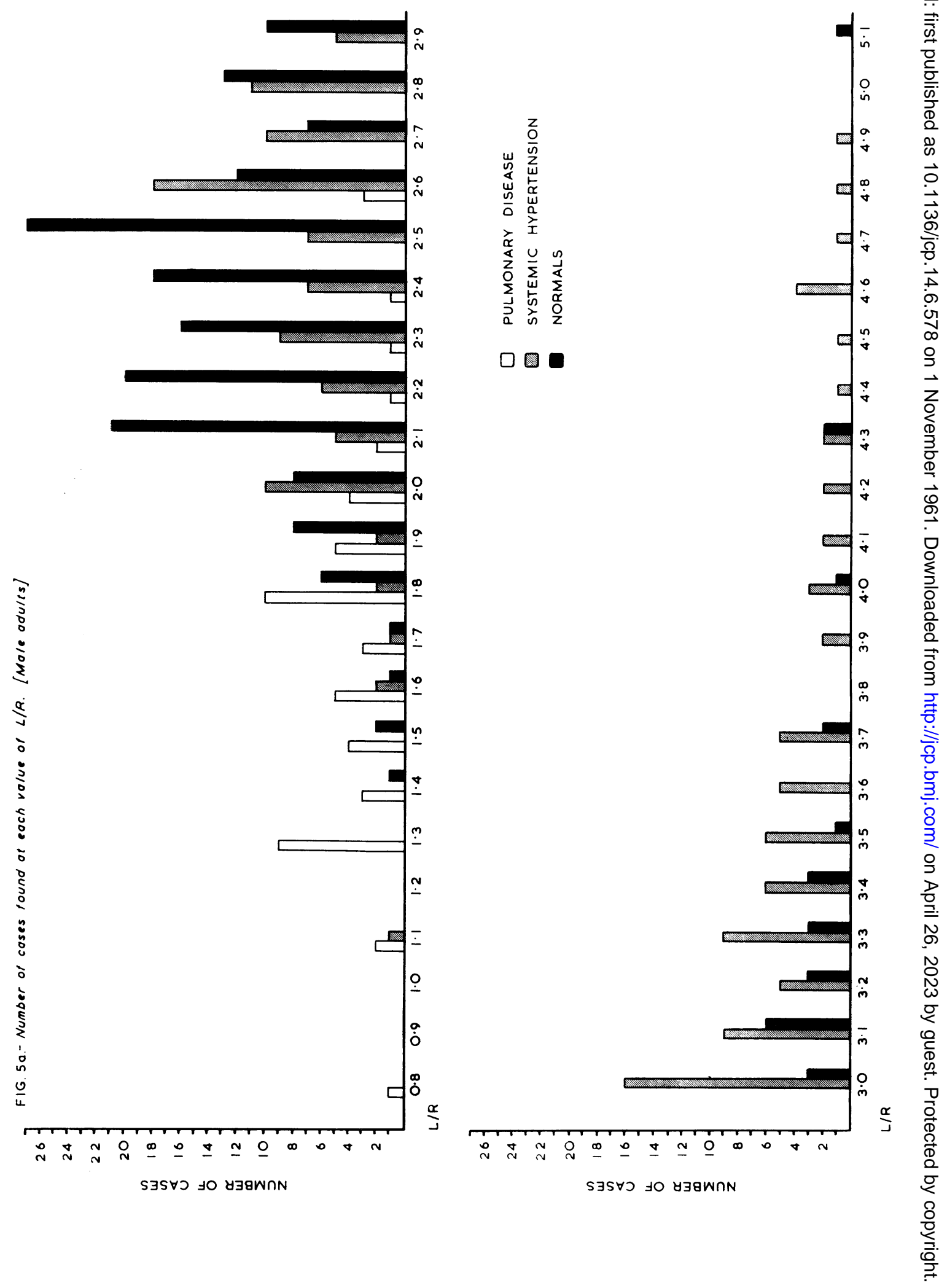




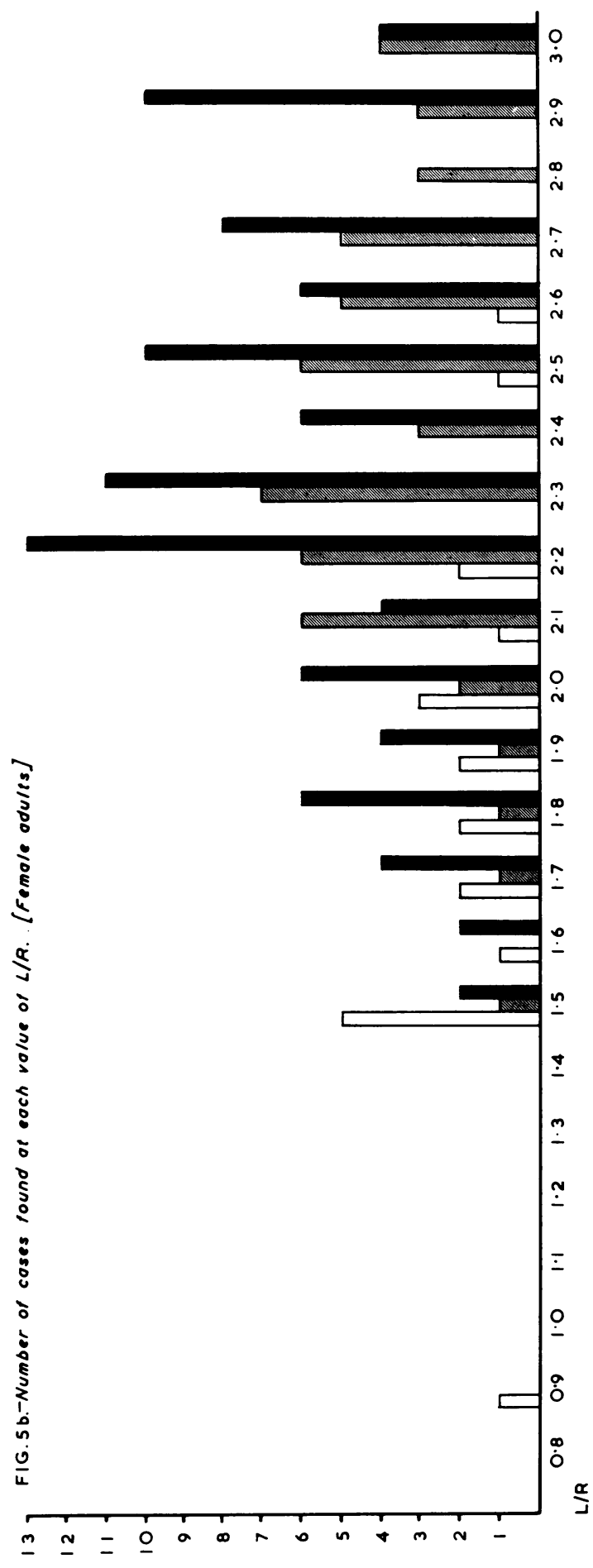

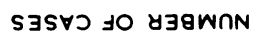

政

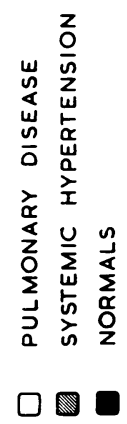




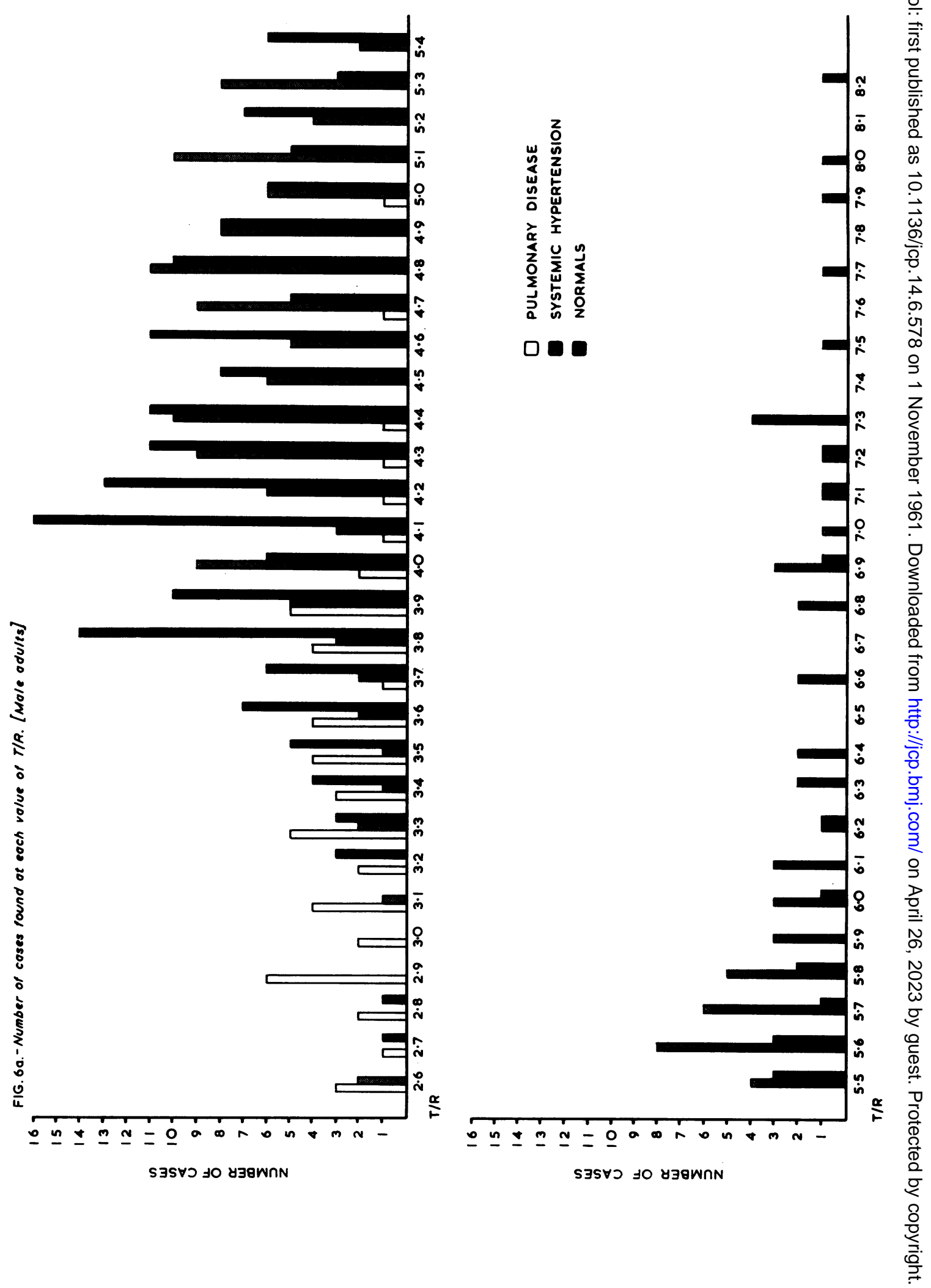




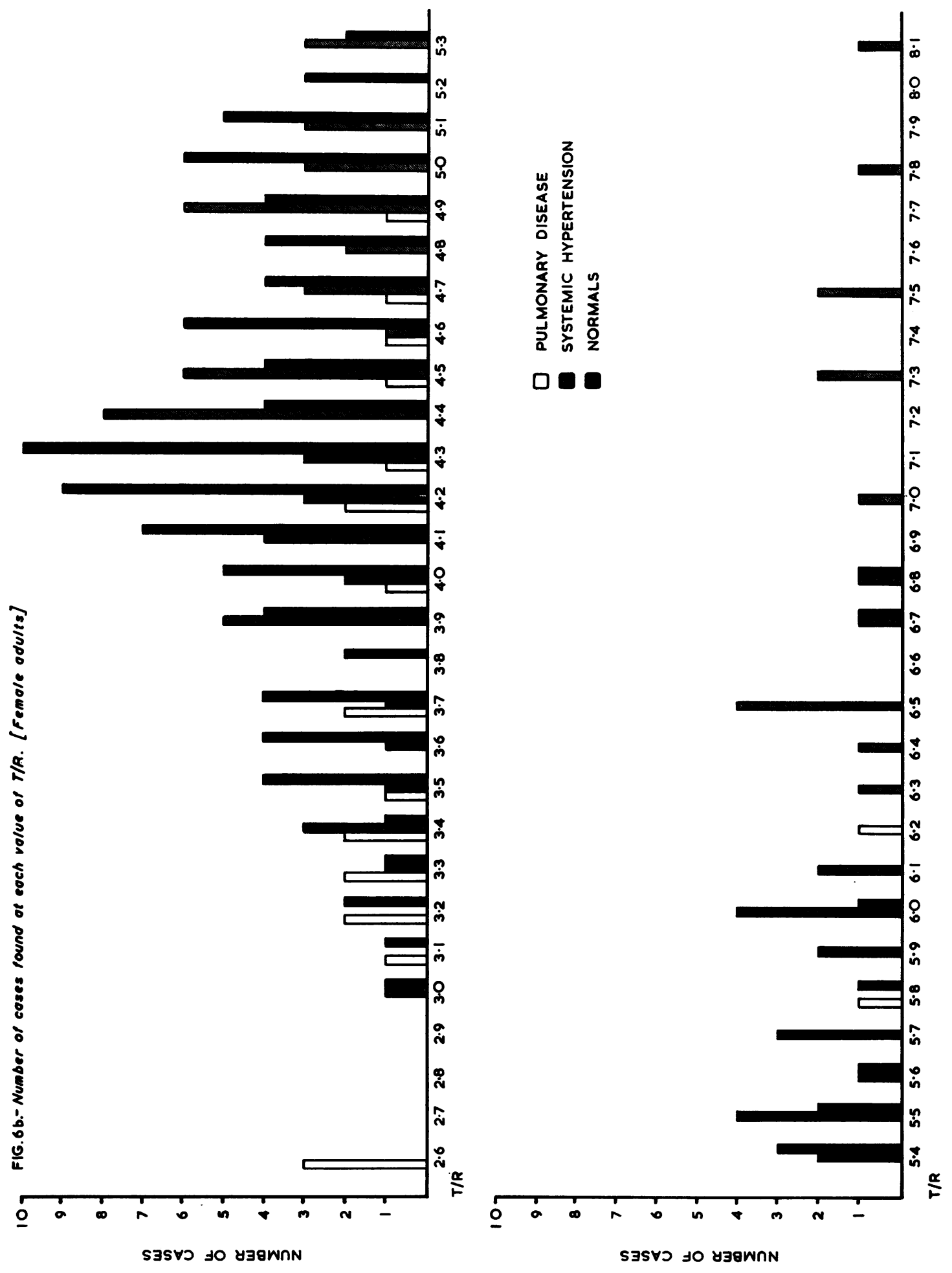




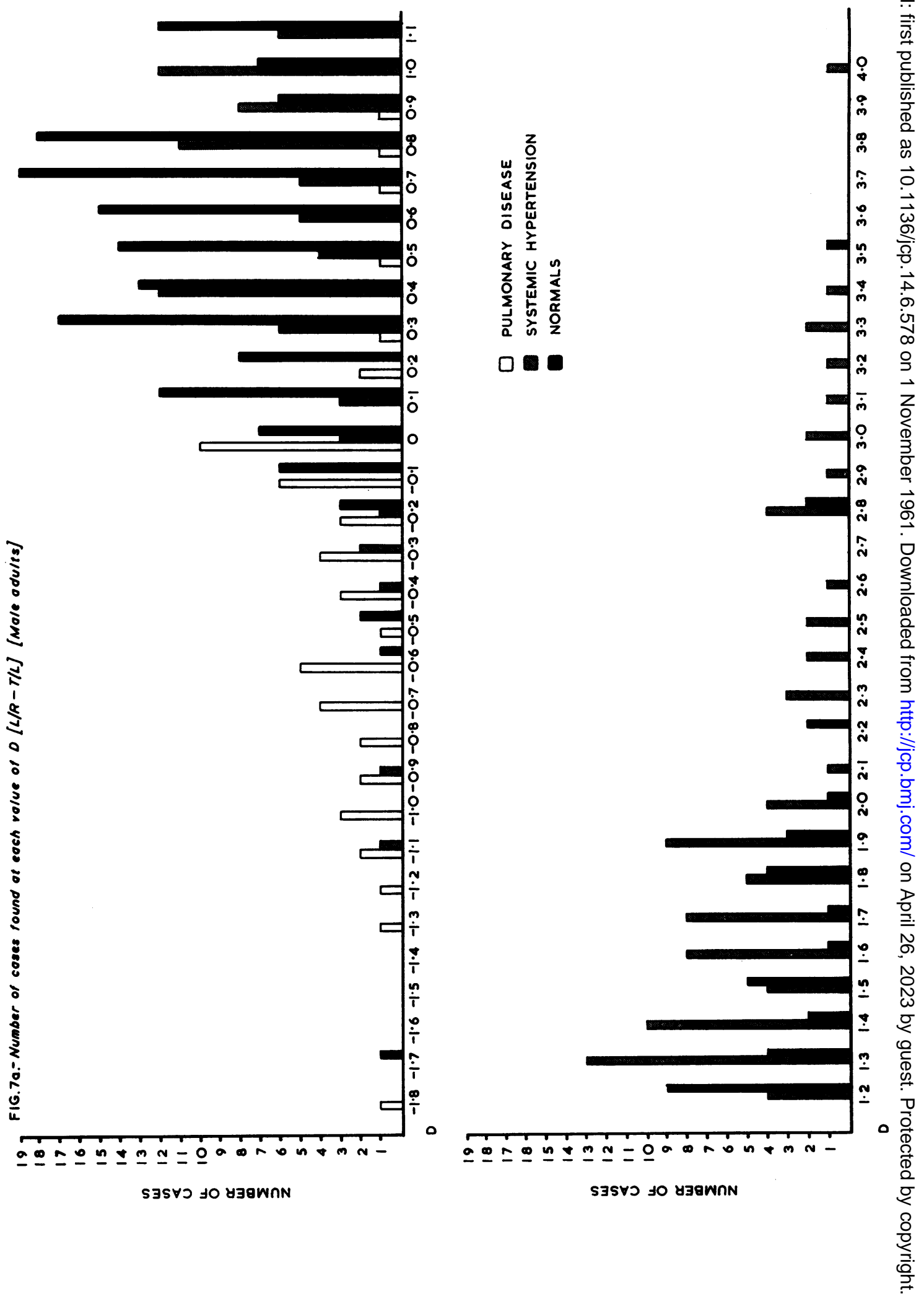



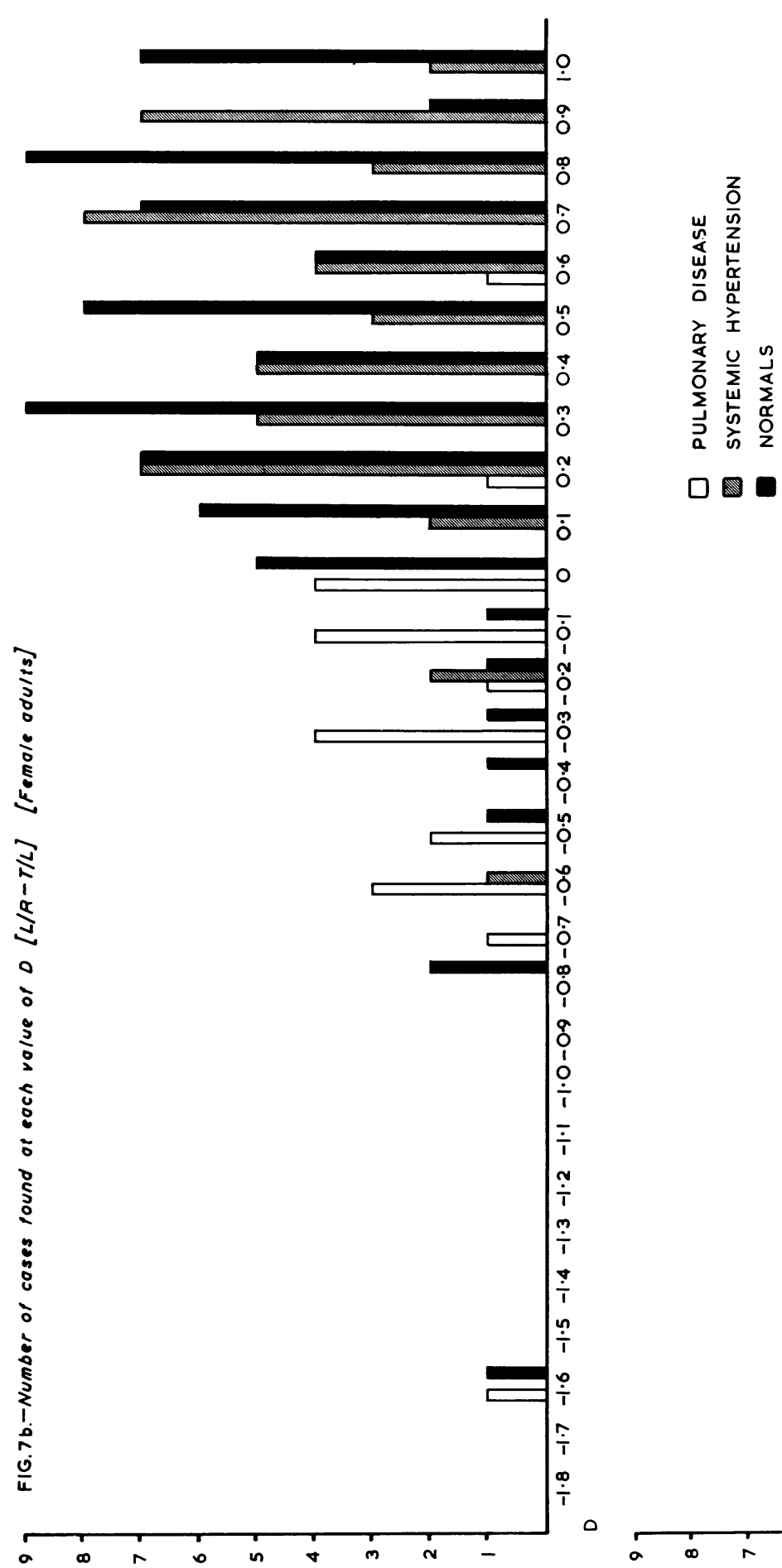
hEART WEIGHT (MALE)

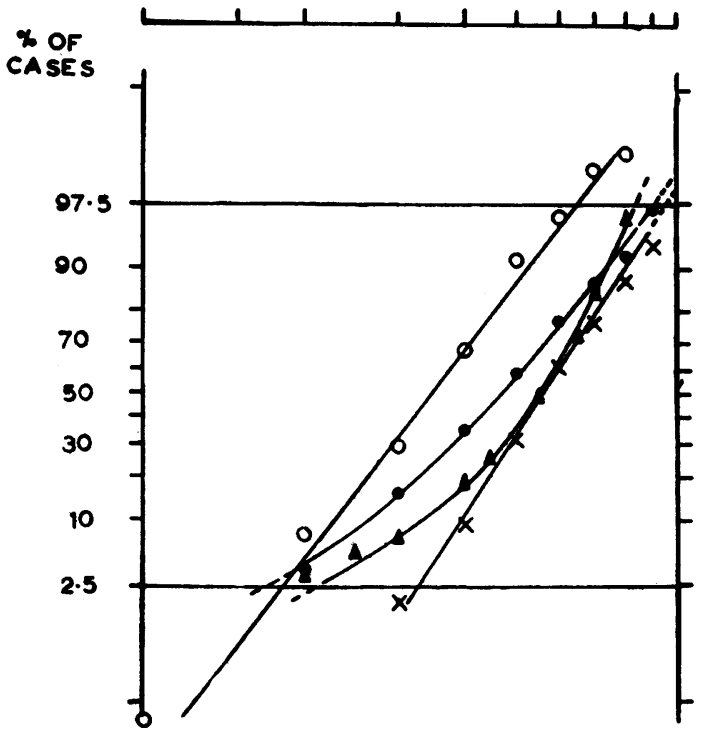

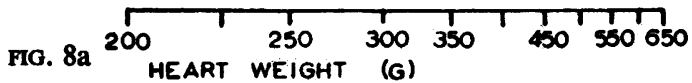
HEART WEIGHT (FEMALES)

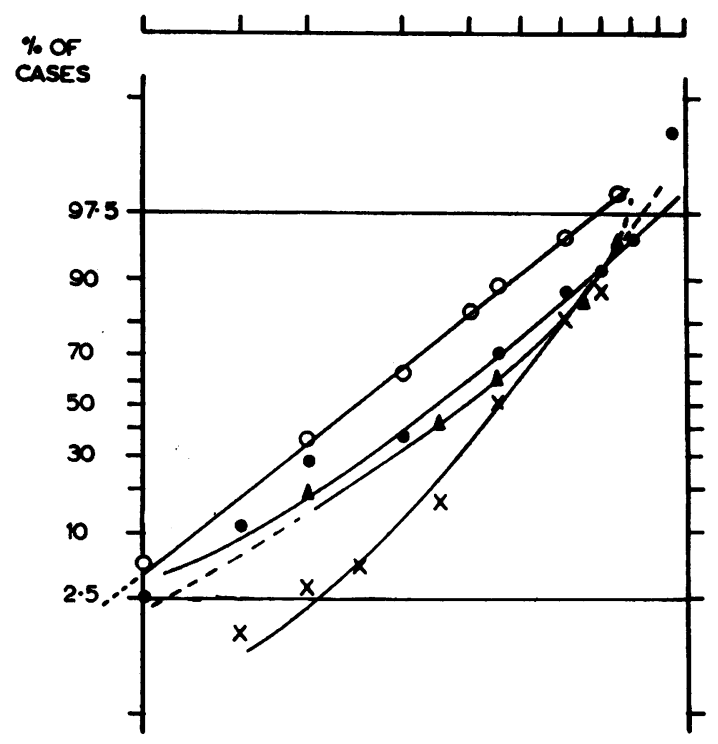

FIG. $8 \mathrm{~b} 200$ TEART WEISHT (G) ${ }_{\substack{250 \\ \text { HEA }}}^{100}{ }_{500}^{T} 600$
LIR (MALES)

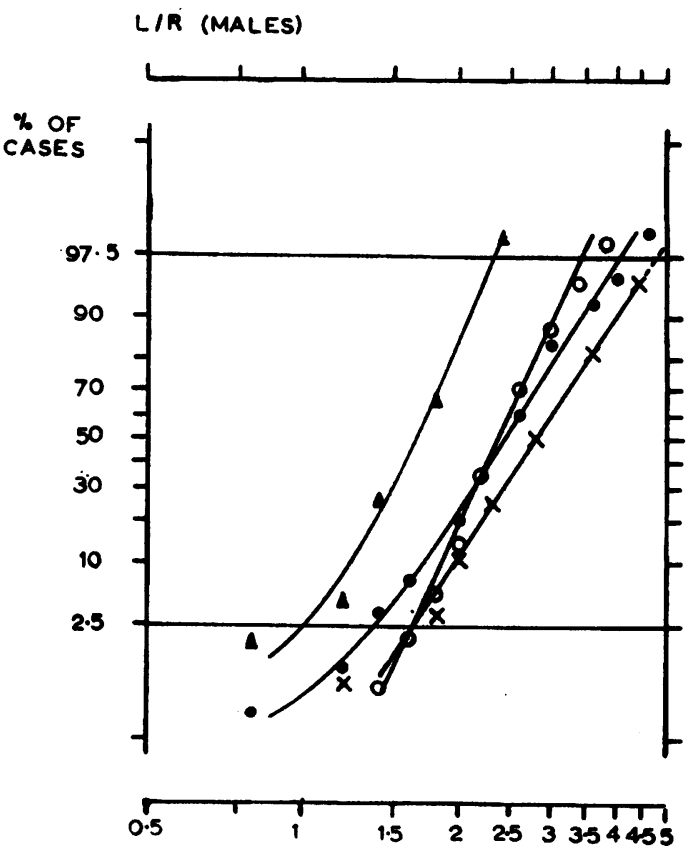

FIG. 9a

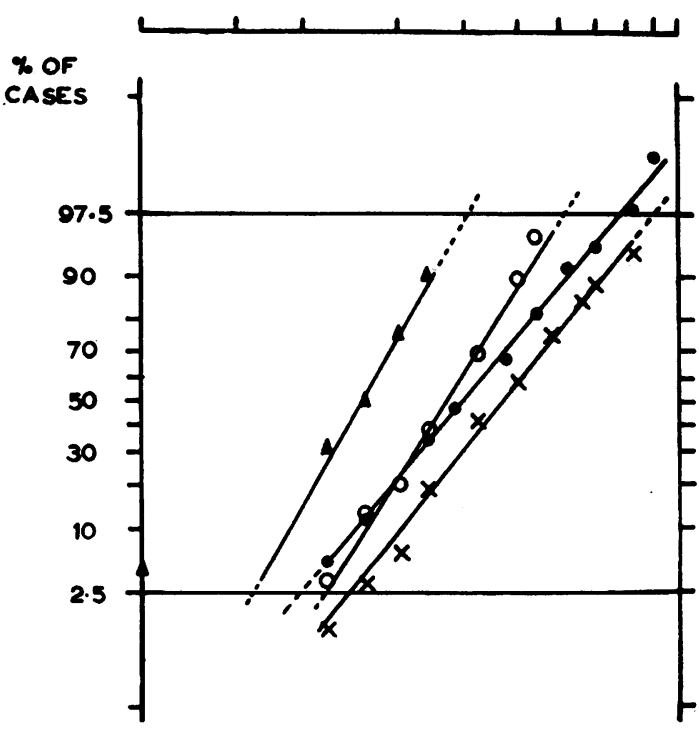

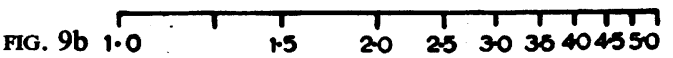

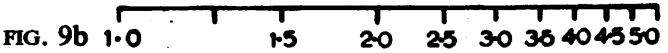


TIR (MALE)

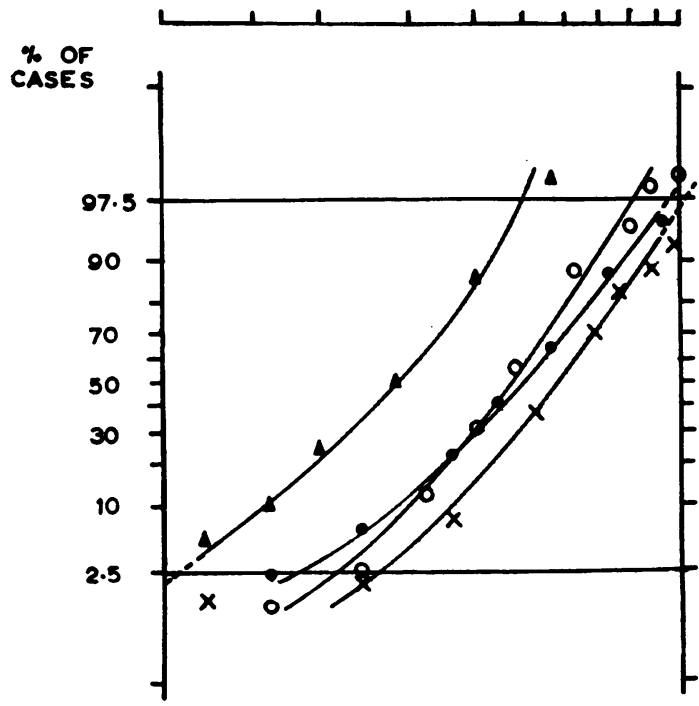

FIG. $10 \mathrm{a}$

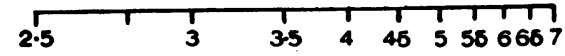

T/R (FEMALES)

\% of CAses

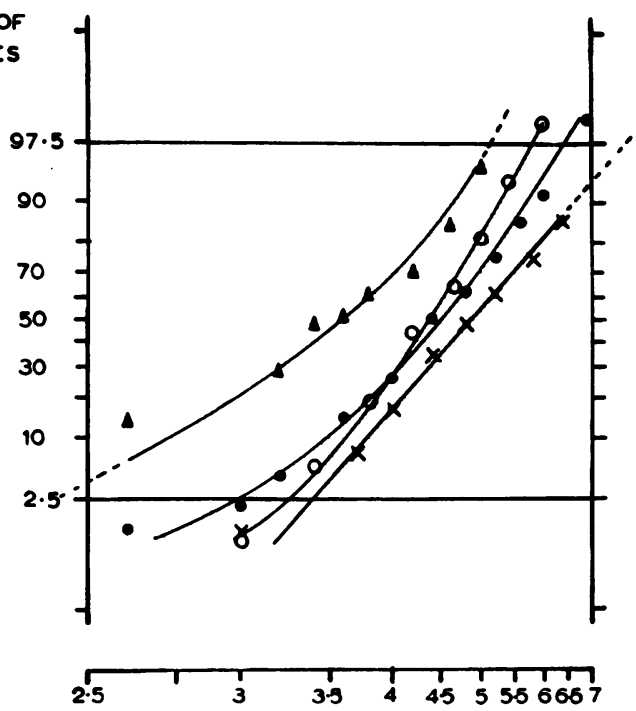

FIG. $10 b$
D (males)

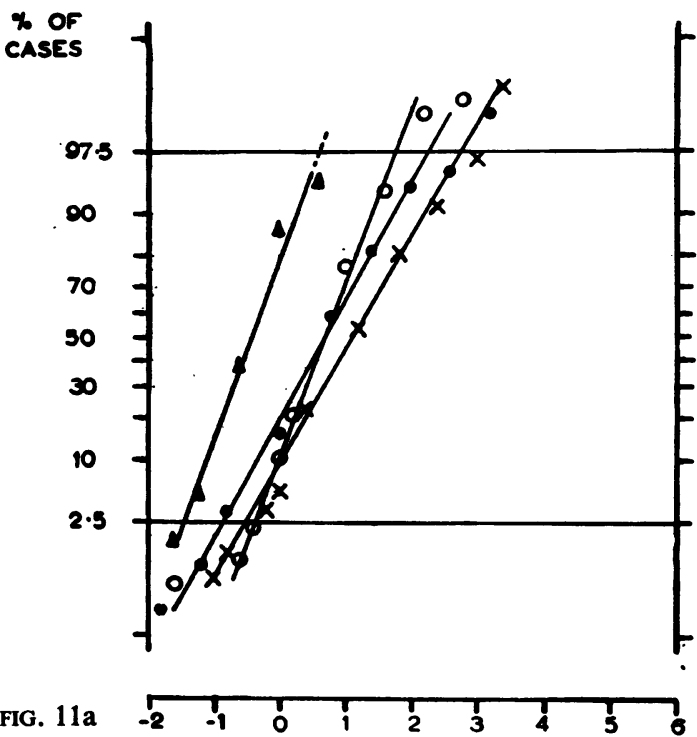

D (females)

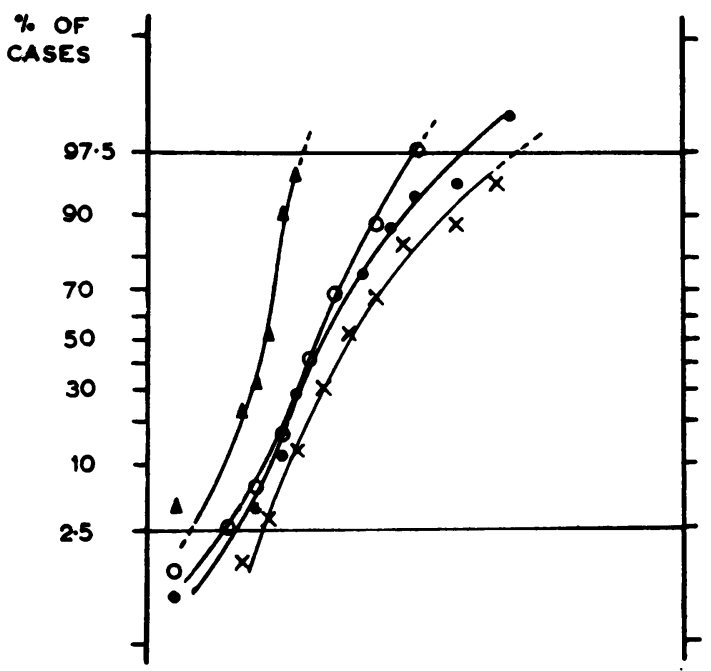

FIG. $11 b$ 
and may be associated with the interpretations which we have put on them. Although these calculations are approximate, there seems no reason to suppose that more laborious and exact methods would lead to different conclusions.

HEART WEIGHT ANALYSIS ACCORDING TO DISEASE Three diseases of the pulmonary system were extracted from Table $I$ in order to determine if it is legitimate to include them in a category which is so suggestive of pulmonary hypertension.

Pulmonary tuberculosis There are seven cases in the 120 with reversed ratios and six cases in the $\mathbf{5 3 0}$ of normal or raised ratios. This difference is significant at the 1 in 1,000 level so that it seems justified to leave them as they stand in Table I.

Carcinoma of lung In the 120 cases with reversed ratios there are 10 cases of carcinoma of lung or bronchus and 25 in the 530 cases in the other groups. These differences are significant only at the 1 in 10 level and it is concluded that this disease is not associated with pulmonary hypertension. This material was therefore withdrawn from the pulmonary group and re-allocated to other categories; the new totals are shown in the final columns of Table I and these figures have been used in the other analyses.
Pulmonary embolism This is acute massive embolism usually post-operative or post-traumatic. There are 17 cases in the 120 with reversed ratios and 29 with normal or raised ratios. This difference being significant at the 1 in 1,000 level suggests that acute pulmonary embolism is associated with pulmonary hypertension and the two are bracketed in the final column of Table $I$.

If the figures in Table I are re-tabulated ignoring the total weight of the heart, much of their significance is lost, especially when the ratios are normal but less so when the ratios are raised or reversed. Perhaps this is due to including more cases of 'uniform hypertrophy' among the normals, but it destroys our hope that use of the fractions would entirely remove the difficulty of defining the weight of the normal heart.

HEART WEIGHTS IN ADOLESCENTS, CHILDREN, AND INFANTS An arbitrary division of this material into these three groups has been mentioned previously. Difficulty in deciding the normal heart weight in these cases (Sunderman and Boerner, 1949), lack of recorded blood pressure readings in almost all cases, and the small numbers prevent any valid analysis, especially in the first two groups. The findings in adolescents and children are shown in Table III

TABLE III

RESULTS IN ADOLESCENTS AND CHILDREN

\begin{tabular}{ll}
\hline Male & \\
\hline $\begin{array}{l}\text { No to } 19 \text { Years } \\
\text { of } \\
\text { Cases }\end{array}$ & \begin{tabular}{l} 
I to 9 Years \\
\hline $\begin{array}{l}\text { No Age } \\
\text { Cases }\end{array}$
\end{tabular} \\
\hline
\end{tabular}

\begin{tabular}{|c|c|}
\hline 10 to 19 Years & 1 to 9 Years \\
\hline $\begin{array}{l}\text { No. Age } \\
\text { of } \\
\text { Cases }\end{array}$ & $\begin{array}{l}\text { No. Age } \\
\text { of } \\
\text { Cases }\end{array}$ \\
\hline
\end{tabular}

\begin{tabular}{|c|c|c|c|c|c|c|c|c|c|c|}
\hline $\begin{array}{l}\text { Ratios } \\
\text { normal }\end{array}$ & 7 & $\begin{array}{l}10 \\
13 \\
13 \\
16 \\
16 \\
17\end{array}$ & $\begin{array}{l}\text { HW } 95 \\
\text { HW } 260 \text { Leukaemia } \\
\text { HW } 230 \text { Appendicitis } \\
\text { HW } 315 \text { Bronchiectasis } \\
\text { HW } 235 \\
\text { HW } 290 \text { Bronchiectasis }\end{array}$ & 6 & No comment & 5 & $\begin{array}{l}11 \\
13 \\
13 \frac{1}{2} \\
14 \\
15\end{array}$ & $\begin{array}{l}\text { HW } 155 \text { Bronchiectasis } \\
\text { HW } 195 \\
\text { HW } 235 \\
\text { HW } 240 \\
\text { HW } 255\end{array}$ & 6 & No comment \\
\hline
\end{tabular}

17 HW 290 Bronchiectasis HW 280 Accident

$\begin{array}{llll}\begin{array}{l}\text { Ratios } \\ \text { raised }\end{array} & 4 & 10 & \begin{array}{l}\text { Drowned, no details } \\ \text { Accident, no details } \\ \text { Cerebral haemorrhage } \\ \text { B.P. 150/70 mm. Hg., } \\ \text { unconscious }\end{array} \\ & 14 & \begin{array}{l}\text { Rheumatic carditis } \\ \text { Rhe }\end{array}\end{array}$

$2 \frac{1}{2}$ HW 70 Leukaemia 3 HW 60 Leukaemia 3 HW 85 Miliary tuberculosis

5 HW 85 Brain tumour 6 HW 220 Coronary thrombosis. No B.P. reading

$\begin{array}{lllllll}\begin{array}{l}\text { Ratios } \\ \text { reversed }\end{array} & 2 & \begin{array}{l}10 \\ 14\end{array} & \begin{array}{l}\text { Mitral stenosis } \\ \text { Collapse, cor pulmonale }\end{array} & 1 & 6 & \begin{array}{l}\text { Rheumatic carditis } \\ \text { HW } 100\end{array}\end{array}$


TABLE IV

RESULTS IN INFANTS

\begin{tabular}{|c|c|c|c|c|}
\hline \multirow{3}{*}{$\begin{array}{l}\text { Ratios } \\
\text { normal }\end{array}$} & \multicolumn{2}{|c|}{ Male } & \multicolumn{2}{|c|}{ Female } \\
\hline & \multicolumn{2}{|c|}{ No. of Cases } & \multicolumn{2}{|c|}{ No. of Cases } \\
\hline & 18 & $\begin{array}{l}\text { All ages } \frac{1}{2} \text { hr. to } 1 \text { year, premature and stillbirth } \\
\text { Two congenital heart disease, } 3 \text { days and } 1 \text { month } \\
\text { One abnormal kidneys and ureters, } 9 \text { days } \\
\text { No cases of hydrocephalus }\end{array}$ & 11 & $\begin{array}{l}\text { All ages still birth to } 5 \text { weeks and premature } \\
\text { One case hydrocephalus } \\
\text { One intussusception, } 11 \text { weeks }\end{array}$ \\
\hline $\begin{array}{l}\text { Ratios } \\
\text { raised }\end{array}$ & 9 & $\begin{array}{l}\text { Two with abnormal kidneys and ureters, stillbirth and } \\
\text { six weeks } \\
\text { Two hydrocephalus, } 4 \text { months and } 20 \text { months }\end{array}$ & & One hydrocephalus and spina bifida 10 weeks \\
\hline $\begin{array}{l}\text { Ratios } \\
\text { reversed }\end{array}$ & 31 & $\begin{array}{l}\text { Ratios equal (L/R=T/L) in six, } 2 \text { days to } 2 \text { months } \\
\text { Two congenital disease of heart, } 1 \text { week to } 6 \text { weeks } \\
23 \text { all under } 5 \text { days except two at } 14 \text { and } 12 \text { days pre- } \\
\text { mature, one at } 10 \text { days no history, one at } 26 \text { days, hydro- } \\
\text { cephalus }\end{array}$ & 24 & $\begin{array}{l}\text { Two congenital disease of heart } \\
21 \text { all under } 5 \text { days except one at } 5 \text { days hydrocephalus }\end{array}$ \\
\hline
\end{tabular}

and it will be seen that there is some suggestion that they are similar to those in adults. Two boys and one girl with normal ratios had bronchiectasis and it is probable that pulmonary hypertension with right ventricular hypertrophy had not yet become established at this age. Attention is drawn to the interesting possibility of systemic hypertension in two boys aged 14 and 6 years with raised ratios and also in two girls aged $5 \frac{1}{2}$ and $2 \frac{1}{2}$, the latter with renal disease. It will be further noted that two of the four cases with reversed ratios would be expected to have pulmonary hypertension.

The findings in 95 necropsies on infants are shown in Table IV and they suggest that the ratios, which are usually reversed at birth (as would be expected), begin to conform to the adult pattern at about a week or soon afterwards. Some possible reasons for a departure from this rule are also shown in Table IV.

The final conclusions may be re-stated simply: (1) When $L / R \geqslant 3$ and/or $T / R \geqslant 5$, there is left ventricular hypertrophy which, other causes being excluded, is suggestive of systemic hypertension. This association is enhanced if the weight of the heart is increased. (2) When $L / R-T / L$ (D) is 0 or less, other causes being excluded, there is strong evidence of pulmonary hypertension. This association is largely independent of total heart weight and such values are unlikely to be found in the presence of cardiac hypertrophy consequent on systemic hypertension. Conversely it is most unlikely that pulmonary hypertension is present when $L / R \geqslant 3$ and/or $T / R \geqslant 5$.

\section{DISCUSSION}

It is important to stress that these figures can only be regarded as useful when they are considered with the whole of the clinical and post-mortem findings. In these circumstances a departure from normal ratios, whatever the weight of the heart, requires explanation and the method has therefore some value which is enhanced by its simplicity.

In the past, especially when there was no record of the blood pressure or when such a record might be regarded as unreliable owing to the clinical deterioration of the subject, there has been a tendency to consider an increased heart weight suggestive of systemic hypertension, other explanations being lacking. This new technique has to some extent defined more clearly the criteria on which such a conclusion could be sustained and has revealed a method by which pulmonary hypertension can be diagnosed after death.

The finding that acute pulmonary embolism is associated with pulmonary hypertension emphasizes the risk of post-operative and post-traumatic immobilization in patients with chronic pulmonary disease. Such people may be considered as especially suitable for early prophylactic anticoagulant therapy. Their extra susceptibility to this complication is presumably due to venous stasis consequent on the pulmonary hypertension and of course the added risk to such individuals is not confined to immobilization in hospital but is also present when they are confined to bed at home. Phear (1960), in a followup study of patients surviving pulmonary embolism, found that nearly $15 \%$ were severely disabled by pulmonary hypertension. It seems from our own findings that this condition was probably present before the embolic episode which in these severely disabled survivors may have accentuated it.

These results were compared with those published in detail by Lewis (1914) and by Herrmann and Wilson (1922) by calculating the ratios $L / R, T / R$, and $T / L$ from their figures after adding the weight of the septum to their left ventricular weight. In the latter case, although the septum was divided, a reasonably good correlation was found with these conclusions, but in Lewis's tables no such correlation could be found. Herrmann and Wilson remark that 
Lewis's method is inaccurate to the extent of $18 \mathrm{~g}$. lost on one ventricle and calculations from his figures show that they deviate from these, chiefly in the ratios $T / R$ and $T / L$.

It seems that the value of this method is enhanced by its applicability to either sex at any age and its apparent validity in children and infants should be of special interest.

I wish to acknowledge my gratitude to Professor J. R. Squire and members of his staff for their help with the statistical analyses and for some of the figures.

Dr. Avril Oatway has given much help both with necropsies and tabulating results. Other pathologists who performed necropsies are Dr. Martin Israel, Dr. Allan
Jacobs, Dr. C. B. Whittaker, Dr. B. Godwin, Dr. H. G. Alton, Dr. Hameed.

Mr. H. J. Flewitt weighed and recorded all the material and we express our special thanks to him.

I wish also to thank Mr. A. Hemsley for drawing Figs. 4-7 inclusive, and Mr. R. Paton and Mrs. R. Harpin for the photographs.

\section{REFERENCES}

Bartels, E. C., and Smith, H. L. (1932). Amer. J. med. Sci., 184, 452.

Heath, D., and Whitaker, W. (1955). J. Path. Bact., 70, 285.

Herrmann, G. R., and Wilson, F. N. (1922). Heart, 9, 91.

Lewis, T. (1914). Ibid, 5, 367.

Phear, D. (1960). Lancet, $2,832$.

Sunderman, F. W., and Boerner, F. (1949). Normal Values in Clinical Medicine. Saunders, Philadelphia and London.

Zeek, P. M. (1942). Arch. Path. (Chicago), 34, 820.

\section{The September 1961 Issue}

\section{THE SEPTEMBER 1961 ISSUE CONTAINS THE FOLLOWING PAPERS}

The artificial kidney and urea clearance D. J. BLACKMORE and $\mathrm{W}$. J. ELDER

A new principle applied to the determination of calcium in biological materials by flame photometry J. $\mathbf{K}$. FAWCETT and V. WYNN

Estimation of gamma globulin in the serum of patients with hypogammaglobulinaemia R. A. KEKWICK, L. vallet, M. CUTBush, P. L. mollison, A. R. THOMAS, P. G. H. GELL, and J. F. SOOTHILL

The antithrombin activity of glucuronic esters of bilirubin M. KOPEĆ, T. DAROCHA, S. NIEWIAROWSKI, and J. STACHURSKA

Studies on the disturbance of glucuronide formation in infectious hepatitis M. F. VEST and E. FRITZ

Rapid incremental methods for the determination of serum iron and iron-binding capacity R. N. BEALE, J. O. BOSTROM, and R. F. TAYLOR

Lipids in cadaver sera after fatal heart attacks J. B. ENTICKNAP

Serum alkaline phosphatase fractionation as an aid to diagnosis K. B. COOKE and JOAN F. ZILVA

The determination of 3-methoxy 4-hydroxy mandelic acid in urine. A. J. WorwoD and R. KNIGHT

Factors concerned in the efficient steam sterilization of surgical dressings R. J. FaLLON

A case of meningitis due to Listeria monocytogenes A. BECK

Disinfection of woollen blankets in steam at subatmospheric pressure v. G. ALDER and w. A. GILLESPIE

Nasal abnormality and the carrier rate of Staphylococcus aureus S. I. JACOBS, G. M. WILLIAMSON, and A. T. WILLIS

A contribution to the technique of intracutaneous testing with toxoplasmin OTTO JíROVEC and JNDŘICH JIRA
Antistreptolysin levels in normal infants and young children c. W. POTTER and J. LORBER

Fatal septicaemia due to Salmonella cholerae suis I. s. $\vec{\varphi}$ BAIIEY, G. GARRETT, and A. NICOL

Serum precipitin reactions in Hashimoto's thyroiditis J. M. MOORE

Minimal criteria for the diagnosis of megaloblastic anaemia of pregnancy I. RANNIE and H. MCTAGGART

Antihaemophilic factor deficiency, capillary defect of $\stackrel{\mathbb{Q}}{\mathscr{Q}}$ von Willebrand type, and idiopathic thrombocytopenia $\overrightarrow{\vec{B}}$ occurring in one family E. K. BLACKBURN, J. M. MACFIE, Э J. H. MONAGHaN, and A. P. M. PAGE

Coagulation tests on capillary blood KATHARINE $M$. DORMANDY and R. M. HARDISTY

The anaemia of lead poisoning H. E. HUTCHISON and J. M. STARK

The recognition of Hageman deficiency in blood donors W. L. MARSH and J. JENKINS

Renal enlargement in chronic cor pulmonale P. A. ELLIS

Technical methods

A contact slide method for the isolation of staphylococci $\frac{N}{\sigma}$ I. A. PORTER and JOYCE NICHOLSON

A micro-method for measuring glucose using the Autoanalyzer and glucose-oxidase CYNTHIA WINCEY and VINCENT MARKS

A micro technique for protein concentration suitable $\stackrel{\varrho}{工}$ for quantitative electrophoresis of cerebrospinal fluid $\mathscr{\bigotimes}$ J. COLOVER

The iron method of haemoglobin estimation J. FINE

Book reviews BRITISH MEDICAL ASSOCIATION, TAVISTOCK SQUARE, W.C.1, price 17s. 6D. 